\title{
Noise analysis of a portable aeromagnetic surveying system using a hybrid UAV
}

\author{
Jirigalatu, J.; Andreasen, A. Døssing; Da Silva, E. Lima Simões
}

Published in:

Proceedings of the 3rd Conference on Geophysics for Mineral Exploration and Mining

Link to article, DOI:

10.3997/2214-4609.202020083

Publication date:

2020

Document Version

Publisher's PDF, also known as Version of record

Link back to DTU Orbit

Citation (APA):

Jirigalatu, J., Andreasen, A. D., \& Da Silva, E. L. S. (2020). Noise analysis of a portable aeromagnetic surveying system using a hybrid UAV. In Proceedings of the 3rd Conference on Geophysics for Mineral Exploration and Mining (pp. 1-5). European Association of Geoscientists and Engineers. https://doi.org/10.3997/22144609.202020083

\section{General rights}

Copyright and moral rights for the publications made accessible in the public portal are retained by the authors and/or other copyright owners and it is a condition of accessing publications that users recognise and abide by the legal requirements associated with these rights.

- Users may download and print one copy of any publication from the public portal for the purpose of private study or research.

- You may not further distribute the material or use it for any profit-making activity or commercial gain

- You may freely distribute the URL identifying the publication in the public portal 


\section{Noise Analysis of a Portable Aeromagnetic Surveying System Using a Hybrid UAV}

J. Jirigalatu ${ }^{1}$, A. Døssing Andreasen ${ }^{1}$, E. Lima Simões da Silva ${ }^{1}$

${ }^{1}$ Technical University of Denmark

\section{Summary}

A capable and light-weight aeromagnetic surveying system is invariably preferred because of its cost-effectiveness, low personnel risk, and so on. However, developing such a system requires a solid understanding of noise from the platform on which it is built - an unmanned aerial vehicle (UAV). Therefore, we investigate static and dynamic noise from a hybrid UAV. The static noise from the platform is discontinuous leading to the spiky 4th difference due to radio transmission and cultural noise in the vicinity, whereas the dynamic noise is mainly due to the attitude of the aircraft, which can be reduced by proper aeromagnetic compensation. Consequently, the high noise level requires some painstaking effort to improve the current design of the system, such as increasing the distance between the magnetic sensors and sources of interference. 


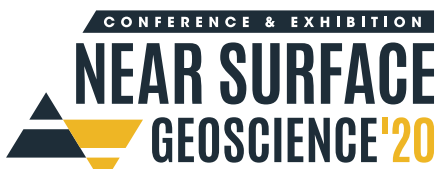

\section{Introduction}

Reliable and high-resolution aeromagnetic data are widely used to serve various geophysical purposes from mineral explorations to mapping the thickness of sedimentary basins and geological structures (Hinze et al., 2013). Aeromagnetic surveys using unmanned aerial vehicles (UAV) because of its costeffectiveness, fast coverage, and low personnel risks has therefore gradually gained its popularity in the aforementioned applications (Tuck et al., 2018; Mu et al., 2020). It signifies a preference and a desire for light-weight and high-resolution airborne magnetic surveying systems in geophysical prospecting. Due to the compact size of UAVs, such surveying systems are often troubled by magnetic interference owing to the magnetometers close to sources of interference/noise, such as motors, electric-powered devices, and even current-carrying wires (Tuck et al., 2018). It is therefore imperative to identify sources of interference and assess the level of severity to further improve the current design and later post-processing strategies. Since we have been developing such kind of portable aeromagnetic data acquisition system built on a hybrid UAV (not only able to take off and land vertically without a runway like multi-rotor UAVs but also having as good aerodynamic performance as fixed-wing UAVs, which means longer battery life, so greater coverage per charge), it is of great importance for us to assess the noise level of the system.

\section{The aeromagnetic surveying system}

To identify sources of interference and locate a favorable area to mount magnetic sensors on the UAV (see Figure 1), we first mapped its magnetic signature. According to Figure 2, the magnetic signature of the wing area is strong and peaks where the servos and the motors are deployed, but gets smaller with the bigger distance away from those highly magnetic UAV components, especially in the areas beyond the wing-tips. However, the flexible wing-tips, designed to adapt to dynamic airflow in-flight, are problematic for aeromagnetic surveys (Tuck et al., 2018). Interestingly, the magnetic signature along the longitudinal axis of the UAV is significantly smaller, especially in the region beyond the UAV's nosetip (Figure 2c). Therefore, we placed two compact magnetometers on a boom mounted on the nose-tip as in Figure 3. The primary magnetometer is responsible for measuring the signal of interest, whereas the secondary sensor placed closer to the nose-tip is used to monitor noise during measurement. It is also worth pointing out that to reduce the net magnetic signature, we also replaced the existing highlymagnetic servos with the one having a smaller magnetic signature.

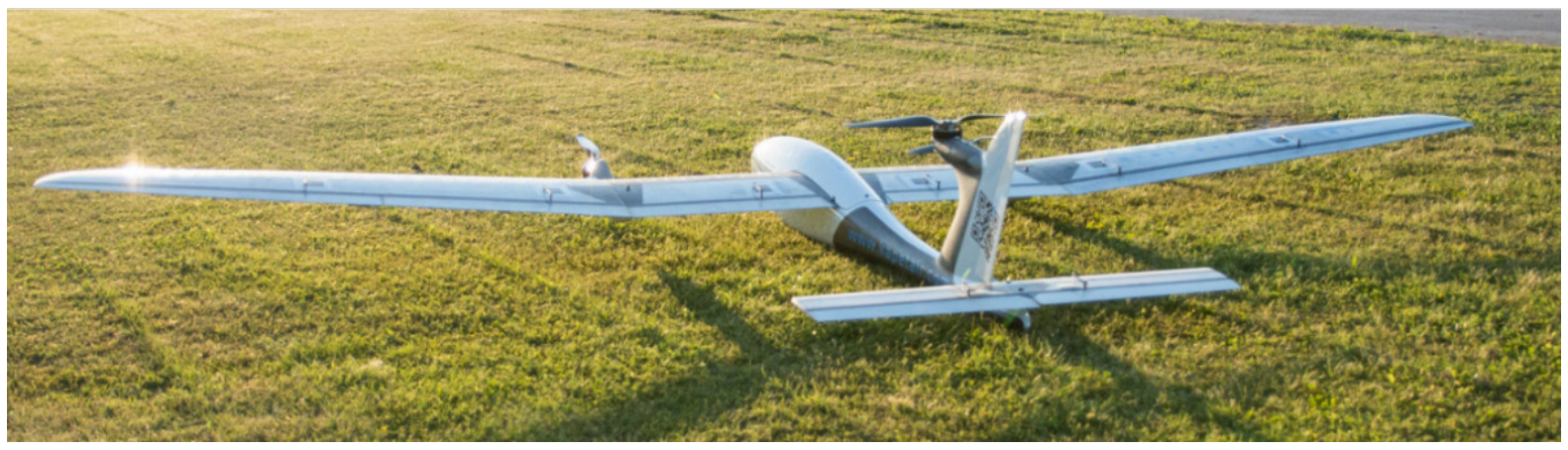

Figure 1 The platform, a mixture of traditional multi-rotor and fixed-wing UAVs.

\section{Test Flight}

To understand the noise of the UAV in operation, we flew a test flight, which took place on 5, March 2020 in Støvring, Denmark. The test site is centered on latitude $56.888^{\circ}$, longitude $9.866^{\circ}$ (Figure 4). The test flight was flown in the manual mode. Both magnetometers are the QuSpin Total-Field Magnetometer (QTFM), a compact, low power, and high-sensitivity scalar magnetometer, capable of sampling geomagnetic field over 200 times per second. 


\section{NEAR SURFACE GEOSCIENCE'2O}

\section{(a)}

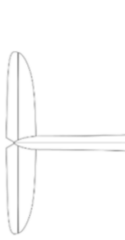

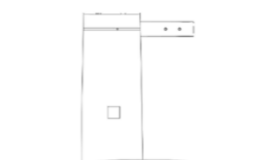

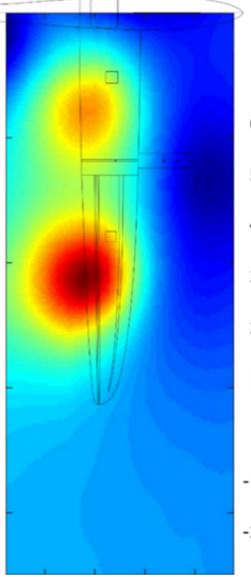

(b)

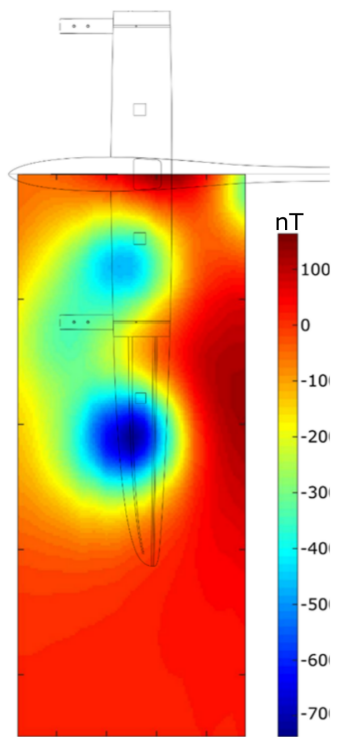

(c)

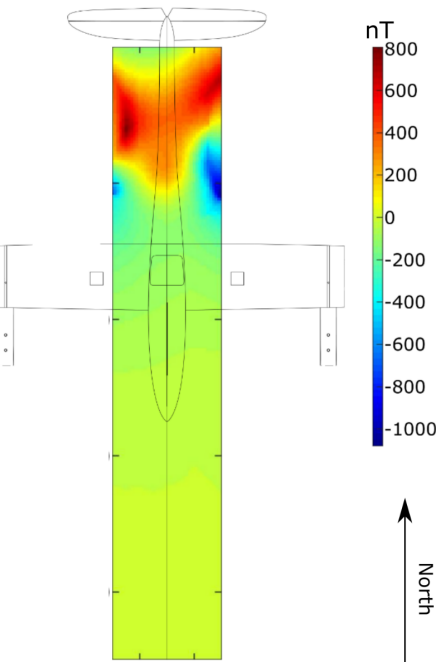

Figure 2 The diurnal-corrected and background-subtracted magnetic signature: (a) the right-wing, $(b)$ the left-wing, and (c) the fuselage.The source-to-measurement distance is $30 \mathrm{~cm}$.

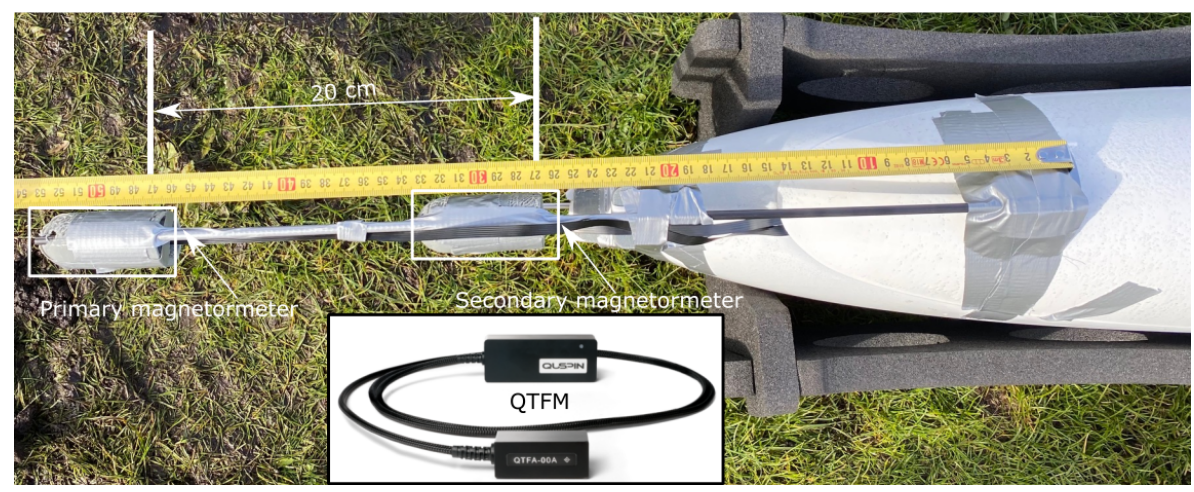

Figure 3 The setup of the boom for the aeromagnetic system.

\section{Static Noise}

We selected two data segments that were magnetically quiet from the primary and the secondary sensors when the UAV was on standby for the static noise analysis (Figure 5). Both plots of the 4th difference are spiky, which means that the measured magnetic field was discontinuous, probably because of powerlines in the vicinity, radio transmission, electrical switching, and so forth. If we assume the noise to be Gaussian, its standard deviation can be used to indicate the noise level of the data. The respective standard deviation of the primary data (measured by the primary sensor) and the secondary data (measured by the secondary sensor) is $0.14 \mathrm{nT}$ and $0.29 \mathrm{nT}$. Such noise can be reduced by either moving the sensors farther away from sources of interference or manual elimination such as non-linear filtering during data reduction (Reeves, 2005).

\section{Dynamic Noise}

As for dynamic noise, it mainly comes from running motors and current-carrying wires as well as other electronic devices, often dependent on maneuvers of the aircraft. From Figure 6, the magnetic data show a strong correlation with the pitch. From our past experience with the setup, we believe that the noise is mainly due to the power wires and because the wires were not fixed to the UAV so they did not follow the maneuver of the UAV in-flight due to inertia. The dynamic noise can be reduced by aeromagnetic compensation, a well-established process for the noise pertaining to the maneuvers in manned aircraft 


\section{NEAR SURFACE GEOSCIENCE 20}
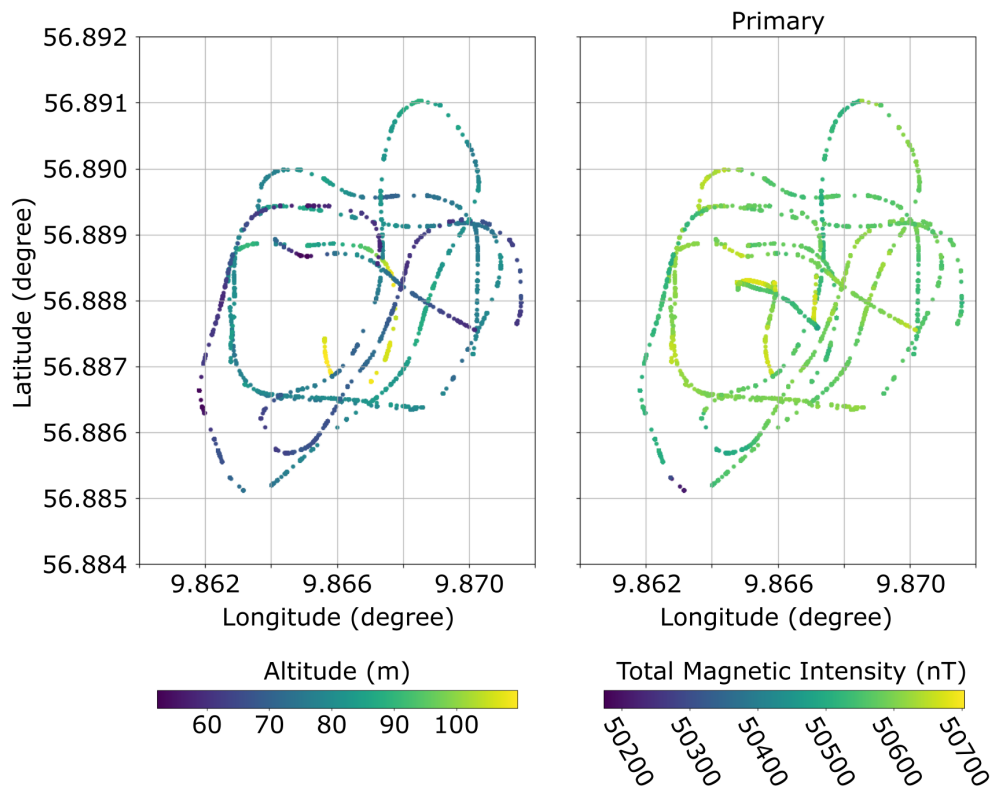

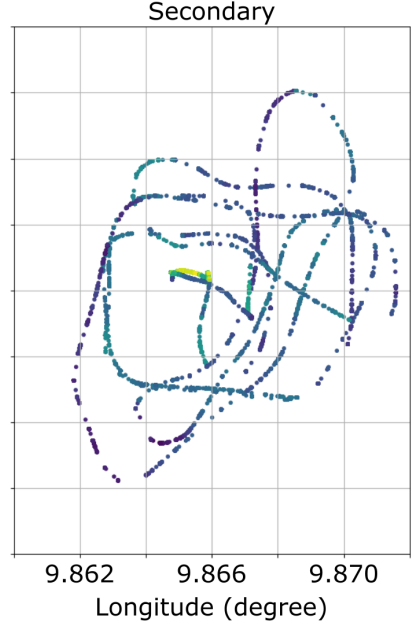

Total Magnetic Intensity (nT)

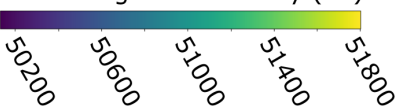

Figure 4 The production flight. The magnitude indicates the altitude in-flight above mean sea level and the final data product.
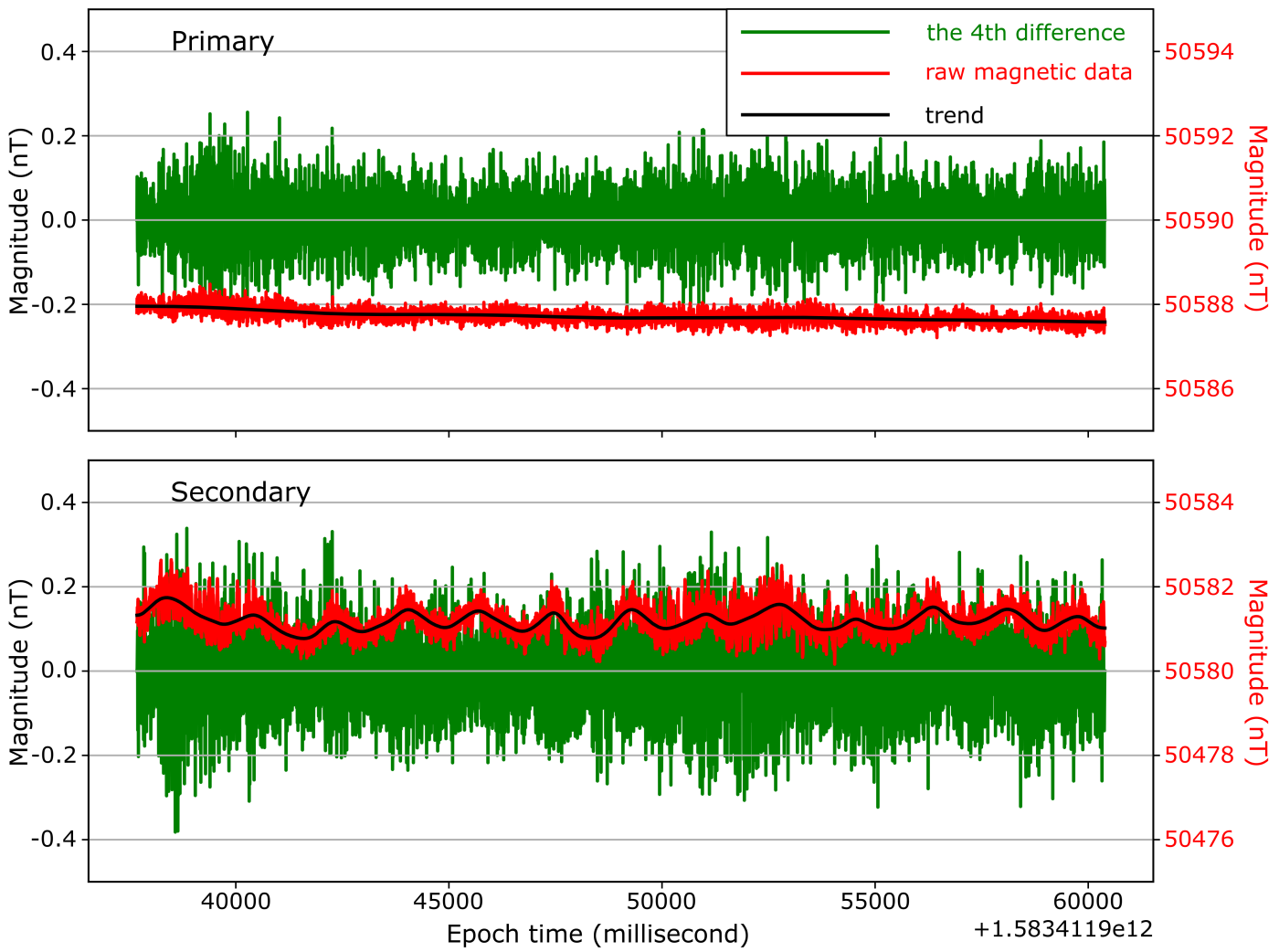

Figure 5 Data excerpts of the raw magnetic data by the primary and the secondary sensors while the drone was on standby.

(Leliak, 1961; Naprstek and Lee, 2017). However, the existing methods can hardly be directly applied to the system we have been developing due to fundamental differences. Therefore, we applied the method proposed by $\mathrm{Mu}$ et al. (2020) to reduce the dynamic noise which can readily take advantage of the complementary magnetic data collected by the secondary magnetometer. The result is shown in Figure 6. The interference is significantly reduced. The standard deviation of the raw primary mag data in 


\section{NEAR SURFACE GEOSCIENCE'2O}

Figure 6 is up to $36 \mathrm{nT}$, but after the compensation, the standard deviation is reduced by $86 \%$ to $5.19 \mathrm{nT}$. But there are still some artifacts left, mainly because of the incompatibility between the two data sets, which means that there are some signals in the secondary data that do not present in the primary data. Interestingly, the plot of the compensated data right goes through the intersections of the plots of the secondary magnetic data and the primary magnetic data in the figure. The intersection points indicate where the interference at the primary magnetometer and the secondary magnetometer drops to around zero for some reason. As a result, the compensated data should be reliable.
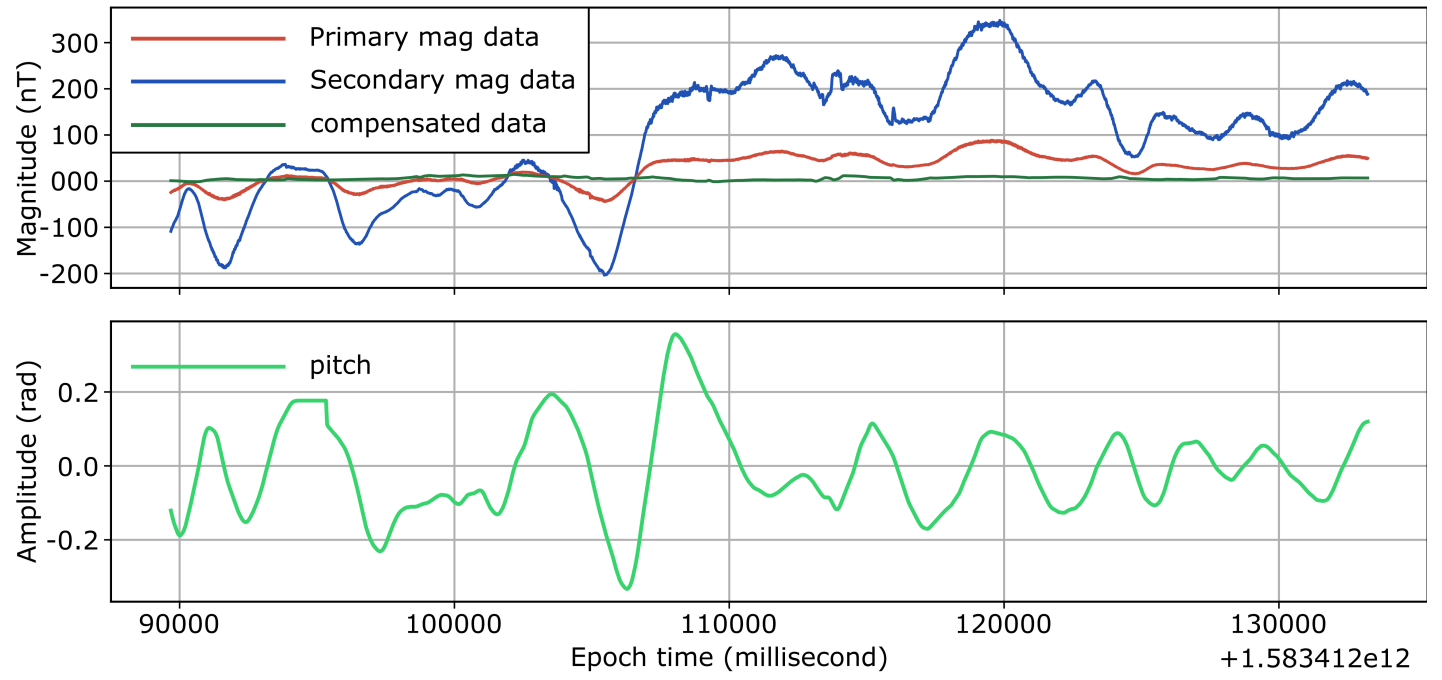

Figure 6 Compensated result of one selected data segment.

\section{Conclusions}

We presented the analysis of the noise of our newly developed aeromagnetic surveying system built on a hybrid UAV. We investigated the static noise and the dynamic noise of the system. The noise level of the system is high, so there is still room for improvement. With the help of the analysis, we have discovered the problems in the system and put forward solutions accordingly, such as moving the magnetometers even farther away from the sources of interference and decreasing the distance between the two sensors to minimize possible incompatibility. Additionally, to reduce the direct correlation with the maneuver of the UAV, we have also planned to make the power wires fixed to the drone, so they no longer move freely.

\section{Acknowledgements}

The project is funded by the European Institute of Technology \& Innovation - Raw Materials (EIT-RM).

\section{References}

Hinze, W.J., Von Frese, R.R. and Saad, A.H. [2013] Gravity and magnetic exploration: Principles, practices, and applications. Cambridge University Press.

Leliak, P. [1961] Identification and Evaluation of Magnetic-Field Sources of Magnetic Airborne Detector Equipped Aircraft. IRE Transactions on Aerospace and Navigational Electronics, ANE-8(3), 95-105.

Mu, Y., Zhang, X., Xie, W. and Zheng, Y. [2020] Automatic Detection of Near-Surface Targets for Unmanned Aerial Vehicle (UAV) Magnetic Survey. Remote Sensing, 12(3), 452.

Naprstek, T. and Lee, M.D. [2017] Aeromagnetic Compensation for UAVs. AGUFM, 2017, NS31A0005-0005.

Reeves, C. [2005] Aeromagnetic surveys: principles, practice \& interpretation. Geosoft.

Tuck, L., Samson, C., Laliberté, J., Wells, M. and Bélanger, F. [2018] Magnetic interference testing method for an electric fixed-wing unmanned aircraft system (UAS). Journal of Unmanned Vehicle Systems, 6(3), 177-194. 